\title{
Uptake of conventional interventions, level of awareness and perception on computer vision syndrome: a cross-sectional study among University students, Kenya
}

\author{
Shadrack Muma $\odot^{1}$, Dickens Omondi Aduda², Patrick Ogola Onyango ${ }^{3}$ \\ ${ }^{1}$ Department of Public Health, Maseno University, Kisumu, Kenya \\ ${ }^{2}$ Department of Public Health, Jaramogi Oginga Odinga University, Bondo, Kenya \\ ${ }^{3}$ School of Graduate Studies, Maseno University, Kisumu, Kenya
}

\begin{abstract}
BACKGROUND: Awareness and perception are critical determinants in the uptake of a health intervention. This study assessed the level of awareness and perception in relation to the uptake of interventions of computer vision syndrome (CVS) among university students.

MATERIAL AND METHODS: From a target population of 21,000 students, 384 students were included in the study. Participants were recruited from Maseno, Kenya. Structured in-depth questionnaires were administered to the participants. Composite awareness scale and summative perception score were used to quantify the level of awareness and perception.

RESULTS: Out of the 384 participants, $48.7 \%$ were males, and $51.3 \%$ females. The study denoted a modal age of $18-24$ years with a mean age of 19.5 years $(S D=0.747)$. The prevalence of CVS was $60.4 \%(n=232)$, and almost half of the participants $(47.8 \%)$ had a low level of awareness. There was a statistically significant difference $(\mathrm{p}=$ $0.001)$ in the level of awareness among participants. Based on perception, nearly three quarter of the participants $(60 \%)$ perceived CVS as a global issue of public health concern in relation to the introduction of portable electronic devices used on a daily basis. Based on CVS precautions, almost half of the participants $(40 \%)$ did not practice the preventive measures.

CONCLUSION: Computer vision syndrome was present in about two out of every five students, while awareness remained significantly low, as well as uptake of preventive measures. We emphasize the need for interventions to increase CVS awareness. Developing an item bank for measuring CVS is desirable.
\end{abstract}

KEY WORDS: level of awareness; perceived susceptibility; practice of interventions

Ophthalmol J 2021; Vol. 6, 1-10

\section{INTRODUCTION}

Computer vision syndrome (CVS) is a binocular anomaly arising from unbalanced accommodation of the eye while using electronic devices $[1,2]$. It is prevalent among computer users due to prolonged period of electronic devices use without proper ob- servation of the existing measures as a result of benefits outweighing the risk. The use of computers, phones and tablets has become more popular, however most users are not aware of the consequences and the severity of CVS progresses slowly without noticing and may worsen daily activities if measures 
are not properly taken [3-7]. Currently, at least 1 billion people have a vision impairment that could have been prevented or has yet to be addressed [8]. Computer vision syndrome is an important emerging cause of preventable vision impairment, alongside other causes such as near-vision loss, refraction disorders, and cataracts. It is among the top 25 causes of years lived with disability (YLDs) globally. Globally, $90 \%$ of computer users suffer from computer vision syndrome; in Africa, $75 \%$ of computer users are estimated to be at risk [9]. The signs and symptoms of CVS are similar to other ocular conditions, and the significant challenge towards uptake of interventions remains a major concern [10].

Consequently, most CVS symptoms go undetected, and the condition may be confused with other eye diseases, which are likely to be incorrectly addressed. Understanding how computer users perceive CVS risk factors and their uptake of related interventions are necessary to improve build up of effective interventions. Clinically, this will help eye care providers effectively diagnose CVS and differentiate it from other conditions which presents with similar symptoms.

Computer vision syndrome remains a confusing condition due to its presentation. Literature defines CVS as experiencing eye strains, tired eyes, sore eyes, watering eyes, irritation of eyes, dry eyes, blurred vision, slowness of focus change and double vision while using a computer. This definition is useful in setting global standards to reduce CVS severity and improve productivity. However, CVS benefits should be aiming at achieving a comfort- able ocular function, rather than merely reducing a single symptom.

Due to advancement in technology, most people use computers and other electronic devices; hence CVS prevalence is on rise with a possibility of increased error rate. In Africa, it is estimated to lower productivity by between $4 \%$ and $19 \%$ among computer users in different sectors [11-13]. Awareness of CVS and its risk factors is highly variable across regions, being lower in the developing world than in developed countries [14-18]. Awareness and perception of being at risk for CVS and acknowledgment that prevention behavior is feasible in this population are crucial for planning the prevention and control measures for this group. For example, while CVS awareness may be high, uptake of prevention and control measures may be hindered by a low perception of risk, lack of targeted health promotion, and perceived efficacy. Risk perceptions are essential precursors to improving health-related behaviors recommended for either dealing with or preventing risks $[19,20]$. In Kenya, the current government encourages students and pupils to use electronic devices to transform the country technologically. At the same time level of awareness and uptake of interventions to mitigate CVS is unknown. This study assessed the key measures to ascertain CVS in the Kenyan context. These findings are crucial for clinicians in an eye care practice since differential diagnosis should be considered in patients with chief complaints surrounding allergic conjunctivitis and computer vision syndrome.

\section{MATERIAL AND METHODS STUDY AREA}

The participants were recruited from Maseno University, Western Kenya. Maseno University is the only higher educational institution in Western Kenya where all programs are incorporated with information technology.

\section{STUDY DESIGN}

This was a cross-sectional study conducted between $1^{\text {st }}-7^{\text {th }}$ July 2019.

\section{STUDY POPULATION}

The study participants included students aged 18-39 years. Students who had low vision were excluded from the study. A total of 384 participants were included in the study. The sample size was arrived at through a simple random sampling.

\section{DATA COLLECTION}

Data was collected through questionnaires with the help of research assistants who were trained on what is CVS and what exactly they needed to collect from the participants.

Ethics approval was granted by Maseno University institutional review board, and the authority to conduct was obtained from the study from National Commission, Science, and Technology.

The questionnaire transcripts were reviewed page by page to check for completeness. Coding was carried out by the corresponding author in the Statistical Package for Social Science version 17. All the authors reviewed the analysis.

\section{RESULTS \\ SUMMIARY OF VARIABLES CHARACTERISTICS \\ We administered questionnaires to 384 par- ticipants (mean age -19.5 years; male: $48.7 \%$;}


Table 1. Summary of variable characteristics

\begin{tabular}{|c|c|c|c|c|c|}
\hline \multicolumn{2}{|c|}{ Variable and variable characteristics } & \multirow{2}{*}{$\begin{array}{c}\text { Count } \\
187\end{array}$} & \multirow{2}{*}{$\begin{array}{c}\text { Proportion } \\
48.7\end{array}$} & \multicolumn{2}{|c|}{ p-value $95 \% \mathrm{Cl}$} \\
\hline Gender & Male & & & .09 & $0.52-0.73$ \\
\hline veriue! & Female & 197 & 51.3 & & $0.53-0.66$ \\
\hline \multirow{4}{*}{ Age } & $18-24$ & 230 & 59.9 & & $0.54-0.79$ \\
\hline & $25-29$ & 80 & 20.8 & & $0.26-0.74$ \\
\hline & $30-34$ & 54 & 14.1 & .001 & $0.49-0.64$ \\
\hline & $35-39$ & 20 & 5.2 & & $0.57-0.71$ \\
\hline
\end{tabular}

The table shows the confidence interval (Cl), the $\mathrm{p}$ value and the proportion of respondents

Table 2. Prevalence of computer vision syndrome (CVS)

\begin{tabular}{|c|c|c|c|c|c|c|}
\hline \multicolumn{2}{|c|}{ Variables } & \multicolumn{2}{|c|}{ CVS absent } & \multicolumn{2}{|c|}{ CVS present } & \multirow[t]{2}{*}{$\mathrm{p}$ value } \\
\hline & & Count & $\%$ & Count & $\%$ & \\
\hline \multirow{4}{*}{ Age } & $18-24$ & 30 & 13 & 136 & 59.1 & \\
\hline & $25-29$ & 94 & 61.8 & 50 & 21.6 & .001 \\
\hline & $30-34$ & 18 & 11.8 & 36 & 15.5 & \\
\hline & $35-39$ & 10 & 21.6 & 10 & 4.3 & \\
\hline \multirow{2}{*}{ Gender } & Male & 81 & 43.4 & 106 & 56.6 & .09 \\
\hline & Female & 71 & 36 & 126 & 64 & \\
\hline
\end{tabular}

The table shows whether computer vision syndrome is present based on age and gender with the $p$ value

female: $51.3 \%$; $S D=0.74)$. The participant's modal age group was $18-24$ years $(59.9 \%)$, the least numerous age group was 35-39 years - 5.2\%. Participants aged 18-24 years were 1.40 times [95\% confidence interval (CI): 0.94-1.73] likely to report CVS symptoms compared to those aged 34-39 years $(\mathrm{p}=.054)($ Tab. 1$)$.

\section{PREVALENCE OF COMPUTER VISION SYNDROME}

Regarding gender, $56.6 \%$ of the males had CVS compared to $64 \%$ of the females. Eye irritation was the most typical symptom reported by the participants $(62.2 \%)$, while eye strain was the least symptom experienced (45.8\%). Most participants aged 18-24 years $(59.1 \%)$ suffered from computer vision syndrome. Participants with CVS were 1.20 times more likely not to take any preventive measure (95\% CI: 0.92-1.44) (Tab. 2).

\section{LEVEL OF AWARENESS OF COMPUTER VISION SYNDROME}

More males were aware that prolonged computer use (95\% CI: 1.31-2.49) was a risk factor for CVS compared with females. Individuals aged 18-24 years were significantly less likely to identify the impact of inappropriate seating position (95\% CI: $0.40-0.74)$ on CVS development compared with older participants. The results showed that 184 subjects $(47.8 \%)$ had a low level of awareness (either not at all aware or slightly aware with scores between 20 to 40 points), 147 (38.2\%) subjects had a medium level of awareness (considered aware of CVS with scores between 41 to 79 points), and $53(13.8 \%)$ had a high level of awareness (moderately or extremely aware with scores between 80 to 100) (Tab. 3).

Perception of computer vision syndrome Compared with females, more males perceived the susceptibility, severity, and benefits (95\% CI: $0.84-1.42$ ) as key to computer vision syndrome. Females were significantly less likely to view perceived susceptibility (95\% CI: $0.36-0.84$ ) as causative to CVS compared to males (Tab. 4).

\section{DISCUSSION}

This study reported CVS prevalence of $60.4 \%$ among university students with a modal age group being 18-24 years. Our results are comparable to those reported among university students in $\mathrm{Ne}$ pal, where the prevalence was $62.6 \%$ [21]. On the contrary, a relatively higher prevalence of $73 \%$ was reported among bank workers in Ethiopia in a population considered to be exposed to computers for 
Table 3. Students' awareness of computer vision syndrome (CVS) $(\mathrm{n}=384)$

\begin{tabular}{|l|c|c|c|c|c|}
\hline \multirow{2}{*}{ Statements } & \multicolumn{5}{|c|}{ Frequency count } \\
\cline { 2 - 6 } & NA & SA & SWA & MA & EA \\
\cline { 2 - 6 } & $\%$ & $\%$ & $\%$ & $\%$ & \multicolumn{2}{c|}{} \\
\hline Awareness of risk factors & 28.4 & 30.5 & 16.4 & 18.5 & 6.3 \\
\hline Period of use & 25.8 & 32.0 & 15.9 & 19.9 & 8.5 \\
\hline Seating posture & 26.0 & 33.1 & 15.4 & 17.4 & 7.6 \\
\hline < arm's length & 25.3 & 32.6 & 16.9 & 17.7 & 7.8 \\
\hline Above eyelevel & 26.8 & 29.7 & 16.9 & 18.8 & 7.24 \\
\hline High brightness & 26.46 & 31.58 & 16.3 & 18.46 & 7.0 \\
\hline Average & & & & & \\
\hline Awareness of preventive measures & 29.4 & 35.7 & 9.6 & 18.2 & 6.5 \\
\hline Regular breaks & 28.9 & 31.8 & 14.8 & 18 & 8.3 \\
\hline Below level & 28.9 & 31.5 & 12.5 & 18.8 & 8.3 \\
\hline Antiglare & 31.0 & 29.7 & 14.6 & 16.4 & 8.0 \\
\hline Contrast & 31.3 & 30.5 & 13.3 & 16.9 & 7.6 \\
\hline Correct error & 29.9 & 31.8 & 12.9 & 14.4 & \\
\hline Average &
\end{tabular}

The table above shows participant responses when asked about being aware of 5 risk factors for CVS and 5 personal preventive measures based on a five level Likert scale: NA - not at all aware; SA — slightly aware; SWA — somewhat aware; MA — moderately aware; EA — extremely aware

a longer time than the average population [5]. This indicates a subtle variation in prevalence across contexts, given differential exposures.
Participants with CVS also reported multiple symptoms, of which eye irritation, an early occurring symptom, was the commonest. These symp-

Table 4. Students perceptions of computer vision syndrome (CVS) by individual susceptibility, symptom severity and benefit of preventive measures $(n=384)$

Variables

\begin{tabular}{|c|c|c|c|c|}
\hline \multicolumn{5}{|c|}{ Frequency Count } \\
\hline SD & D & DK & A & SA \\
\hline$\%$ & $\%$ & $\%$ & $\%$ & $\%$
\end{tabular}

Perceived susceptibility

\begin{tabular}{|c|c|c|c|c|c|}
\hline$<$ than arm's length & 11.2 & 40.6 & 23.2 & 22.1 & 2.9 \\
\hline Prolonged viewing & 8.3 & 29.4 & 30.2 & 28.1 & 3.9 \\
\hline Seating position & 10.4 & 21.4 & 35.2 & 28.1 & 4.9 \\
\hline Above eye level & 9.6 & 24.5 & 38 & 21.9 & 6 \\
\hline Poor light contrast & 9.6 & 20.8 & 38 & 26.3 & 5.2 \\
\hline \multicolumn{6}{|l|}{ Perceived severity } \\
\hline Headache & 16.8 & 22.9 & 33.6 & 31 & 5.7 \\
\hline Eye strain & 5.2 & 20.6 & 29.7 & 36.2 & 8.3 \\
\hline Irritation & 8.9 & 15.6 & 37.2 & 33.1 & 4.3 \\
\hline Eye fatigue & 14.6 & 26 & 27.9 & 25.8 & 5.7 \\
\hline Redness & 7.6 & 23.4 & 38.3 & 24.2 & 4.9 \\
\hline Dry eye & 8.9 & 24 & 38.8 & 15.9 & 4.2 \\
\hline Productivity & 17.7 & 26.3 & 41.1 & 14.3 & 0.5 \\
\hline Error rate & 19.5 & 26.6 & 37.2 & 14.6 & 2.1 \\
\hline Health expenditure & 21.1 & 23.4 & 38 & 15.9 & 1.6 \\
\hline
\end{tabular}




\begin{tabular}{|c|c|c|c|c|c|}
\hline \multirow{3}{*}{ Variables } & \multicolumn{5}{|c|}{ Frequency Count } \\
\hline & SD & D & DK & A & SA \\
\hline & $\%$ & $\%$ & $\%$ & $\%$ & $\%$ \\
\hline \multicolumn{6}{|c|}{ Perceived benefits of preventive measures } \\
\hline Proper contrast & 9.9 & 29.9 & 36.5 & 20.3 & 3.4 \\
\hline Below eye level & 8.1 & 26.6 & 38.3 & 24 & 3.1 \\
\hline Computer glass & 7.3 & 20.1 & 43.8 & 25.8 & 3.1 \\
\hline Arm length & 7.6 & 21.1 & 48.2 & 19.5 & 3.6 \\
\hline Artificial tear & 8.6 & 21.9 & 45.8 & 20.1 & 3.6 \\
\hline
\end{tabular}

The table shows frequencies of participant responses per individual item under each perception variable: perceived susceptibility ( 5 items); perceived severity ( 9 items) and perceived preventive benefits ( 5 items). SD — strongly agree; D — disagree; DK — don't know; $A$ - agree; SA — strongly agree

toms are often subtle and occur simultaneously and more likely to be ignored or confused for other eye conditions, thus presenting diverse diagnosis challenges [5]. This consistent high prevalence among different groups indicates considerable visual burden, whereas concurrent low awareness, risk perception, and uptake of any intervention indicate a high burden on unmet needs among computer users across different contexts.

A slight majority of the students had a low to medium level of awareness of computer vision syndrome, risk factors, and preventive measures, based on a composite awareness scale ranging from 20 to 100. However, the current study did not differentiate between the magnitude of computer use during class hours and non-class hours. A study among university students in India showed that $45.3 \%$ were aware that prolonged computer use is a risk factor of CVS [11].

Computer vision syndrome is an emerging chronic health condition, but information available in literature has not shown the level of awareness on risk factors and preventive measures across population groups. Computer vision syndrome awareness has important implications specifically for occupational health promotion. There is a need to focus health education activities on enhancing awareness of occupational risk factors related to computer usage and the corresponding behavioral preventive measures (including seating position, duration of viewing, distance from the computer screen, and angle of viewing). A high level of awareness, understanding of risk factors as well as preventive measures for CVS are crucial to enable users to make informed health-seeking or prevention decisions since this condition and its risk factors are amenable to primary preven- tions. The current study among university students reported a low level of awareness, with only a few being highly aware. This is possible because CVS is a subtle and insidious condition, with - as yet - low priority among computer users and healthcare providers.

The study revealed that only a few students practiced certain interventions appropriately. Of these practices, only the recommended arm's length screen viewing distance and shorter duration of the current study reported a relatively higher proportion of $46.2 \%$ as compared to a survey among students in Chennai where only $13.7 \%$ used their computers for the recommended duration of time [24]. This is possible because the information applied by the students is from their potential efforts like visiting an eye clinic to see an eye care provider or reading from the internet. In general, awareness has not been enhanced, and this influences the practice of the interventions.

The certain strength of this study was the higher response rate $100 \%$, which was achieved through constant contact between the researchers and the participants.

The limitation of the study was that Kenya has over five universities in the western region, although only one was selected for this survey.

Our study confirms the presence of CVS among students in a tertiary institution, among females than males. Uptake and awareness among computer users on CVS remain low, indicating insufficient public health awareness campaigns. These findings support the need for public health awareness campaigns and occupational health education pertaining to CVS to mitigate its insidious effects. Developing an item bank for measuring CVS is desirable. 


\section{PART A. SOCIO-DEMOGRAPHIC DETAILS}

This section requires that you respond to your personal details like gender and age.

Gender

$\square$ Male

$\square$ Female

Age

$\square$ 18-24 years

$\square 25-29$ years

$\square$ 30-34 years

$\square 35-39$ years

PART B. AWARENESS OF COMPUTER VISION SYNDROME (CVS)

Question 3 to 12 consists of statements on causes and possible interventions of a condition called computer vision syndrome (CVS). Rate them on a scale of 1-5, expressing how much you are aware with each statement. Where $\mathbf{1}=$ not at all aware, $\mathbf{2}=$ slightly aware, $\mathbf{3}=$ somewhat aware, $4=$ moderately aware, $5=$ extremely aware (Tick only the one that applies)

\begin{tabular}{l|l|l|l|l|l|}
\hline Statements & $\begin{array}{c}\text { Not at all } \\
\text { aware }\end{array}$ & $\begin{array}{c}\text { Slightly } \\
\text { aware }\end{array}$ & $\begin{array}{c}\text { Somewhat } \\
\text { aware }\end{array}$ & $\begin{array}{c}\text { Moderately } \\
\text { aware }\end{array}$ & $\begin{array}{c}\text { Extremely } \\
\text { aware }\end{array}$ \\
\hline $\begin{array}{l}\text { Computer vision syndrome is caused by a prolonged } \\
\text { period of computer use }\end{array}$ & & & & \\
\hline $\begin{array}{l}\text { Computer vision syndrome is caused by poor seating } \\
\text { position during computer use. }\end{array}$ & & & & & \\
\hline $\begin{array}{l}\text { Computer vision syndrome is caused by viewing } \\
\text { a computer screen at a distance less than arm's length }\end{array}$ & & & & & \\
\hline $\begin{array}{l}\text { Computer vision syndrome is caused by viewing } \\
\text { a computer screen below the eye level }\end{array}$ & & & & & \\
\hline $\begin{array}{l}\text { Computer vision syndrome is caused by a situation when } \\
\text { the screen brightness is higher than that in the room }\end{array}$ & & & & & \\
\hline $\begin{array}{l}\text { A computer user can reduce CVS by taking regular breaks } \\
\text { during computer use }\end{array}$ & & & & & \\
\hline $\begin{array}{l}\text { A computer user can reduce CVS by viewing the computer } \\
\text { screen below the eye level }\end{array}$ & & & & & \\
\hline $\begin{array}{l}\text { A computer user can reduce CVS by using computer } \\
\text { eyeglasses with antiglare }\end{array}$ & & & & & \\
\hline $\begin{array}{l}\text { A computer user can reduce CVS by maintaining } \\
\text { a balanced contrast between the computer screen } \\
\text { and the room illumination }\end{array}$ & & & & & \\
\hline $\begin{array}{l}\text { A computer user can reduce CVS by correcting } \\
\text { short-sightedness or long-sightedness }\end{array}$ & & & & & \\
\hline
\end{tabular}

\section{PART C. PERCEPTION OF COMPUTER VISION SYNDROME (CVS)}

Question 13 to 31 consists of statements on the perception of a condition called computer vision syndrome (CVS). The sections have been divided into three aspects of perception that is perceived susceptibility (risk factors), perceived severity (consequences of CVS), and perceived benefits (preventive measures). Rate them on a scale of 1-5, expressing how much you agree with each statement. Where $\mathbf{S D}=$ strongly disagree, $\mathbf{D}=\mathbf{d i s a g r e e}$, DK = don't know, $\mathrm{A}=$ agree, $\mathrm{SA}=$ strongly agree (Tick inside the appropriate one)

Perceived susceptibility (risk factors)

\begin{tabular}{|c|c|c|c|c|c|}
\hline Statement & SD & D & DK & A & SA \\
\hline \multicolumn{6}{|l|}{ Viewing a computer screen at a distance less than arm's length is a risk factor of CVS } \\
\hline \multicolumn{6}{|l|}{ Prolonged duration of computer use is a risk factor of CVS } \\
\hline \multicolumn{6}{|l|}{ The inappropriate seating position is a risk factor of CVS } \\
\hline Keeping the computer screen above the eye level is a risk factor of CVS & & & & & \\
\hline Poor contrast of the computer screen and the surrounding brightness is a risk factor of CVS & & & & & \\
\hline
\end{tabular}


Perceived severity (consequences of CVS)

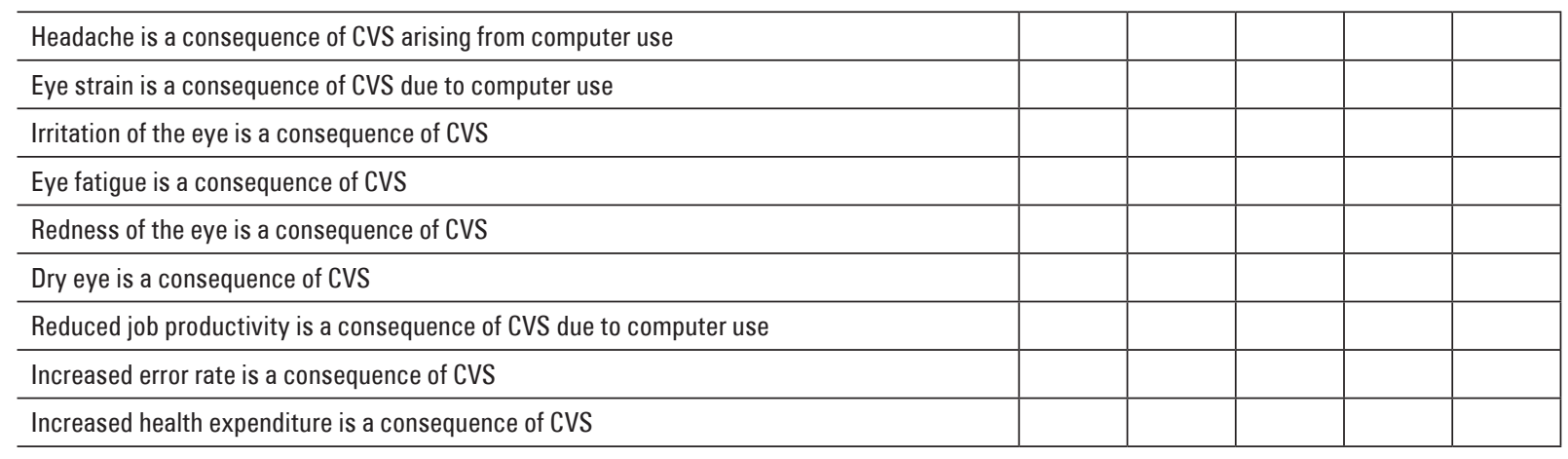

Perceived benefits (preventive measures of CVS).

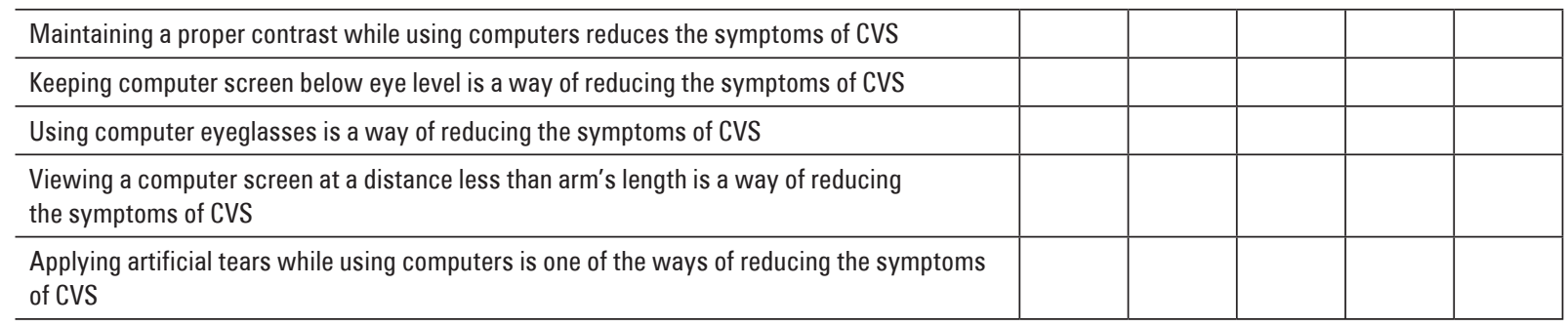

32. Have you heard of the term computer vision syndrome?

$\square$ Yes

$\square$ No

33. Only tick one medium which is most reliable and appropriate for the dissemination of information on CVS. Please do not mark more than one.

$\square$ Radio

$\square$ Internet

$\square$ Television

$\square$ Eye care provider

$\square$ Newspaper and magazine

$\square$ Public library

\section{PART D. PRACTICE OF CONVENTIONAL PREVENTIVE MEASURERS}

This section is about the practice on the uptake of interventions of computer vision syndrome. The section requires that you respond to what you exactly do.

34. Which seating position do you practice below?

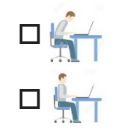

35. At what distance do you view your computer screen?

$\square$ Arm length

$\square$ Less than arm length

$\square$ More than arm length

36 . How long do you use a computer per day?

$\square<3$ hours

$\square$ 3-6 hours

$\square>6$ hours

37. After how many minutes of electronic device use do you take a break?

$\square>20$ minutes

$\square<20$ minutes 
38. Do you use eyeglasses?

$\square$ Yes

$\square$ No

39. If the answer to question no. $\mathbf{3 8}$ is yes, what is the purpose of the eyeglasses?

$\square$ For computer use

$\square$ For vision

$\square$ Not applicable

40. Do you adjust the contrast of your computer with the surrounding brightness?

$\square$ Yes

$\square$ No

41. Do you use antiglare for your computer screen?

$\square$ Yes

$\square$ No

Tick the symptoms you frequently experience in your eyes while using a computer

1. Do you often experience the following symptoms while using computer? (Tick the symptoms you experience).

2. Symptoms associated with headache while using electronic devices (Asthenopic symptoms).

$\square$ Eye strain (a feeling of discomfort in the eye muscles)

$\square$ Tired eyes (a symptom which makes one not to feel like opening the eye due to discomfort)

3. Ocular surface-related (symptoms experienced in the eye due to environmental exposure while using electronic devices).

$\square$ Watering eye (eyes removing water every time you are using an electronic device)

$\square$ Irritation (eyes becomes itchy and feeling of foreign body in the eye)

$\square$ Dry eye (experiencing pain in opening and closing the eye due to tear insufficiency)

4. Visual symptoms (symptoms that affect the clarity of the eye while viewing objects)

$\square$ Blurred vision (being unable to see objects clearly while using electronic devices and after)

$\square$ Double vision (seeing more than one object while using electronic devices and after)

$\square$ Slowness of focus change (being unable to see a near object and a distant object at the same time)

\section{Acknowledgment}

We thank all the university students for participating in this study.

\section{Author's contributions}

Both authors contributed equally.

\section{Availability of data and materials}

Data is available upon reasonable request from the corresponding author.

\section{Funding}

No funding received.

\section{REFERENCES}

1. Khan R, Surti A, Rehman R, et al. Knowledge and Practices of Ergonomics in Computer users. J Pak Med Assoc. 2012; 62(3): 213-217, indexed in Pubmed: 22764450.

2. Schaumberg DA, Dana R, Buring JE, et al. Prevalence of dry eye disease among US men: estimates from the Physicians' Health Studies. Arch Ophthalmol. 2009; 127(6): 763-768, doi: 10.1001/archophthalmol.2009.103, indexed in Pubmed: 19506195.

3. Mallik D, Gahlot A, Maini A, et al. Prevalence of dry eye amongst computer workers in Kanpur. Int J Commun Med Publ Health. 2017; 4(7): 2308, doi: 10.18203/2394-6040.ijcmph20172523.

4. Logaraj M, Madhupriya V, Hegde S. Computer Vision Syndrome and Associated Factors among Medical and Engineering Students in
Chennai. Ann Med Health Sci Res. 2014; 4(2): 179, doi: 10.4103/21419248.129028, indexed in Pubmed: 24761234.

5. Gupta N, Moudgil T, Sharma B. Computer Vision Syndrome: Prevalence And Predictors Among College Staff And Students. J Dent Med Sci. 2016; 15(9): 28-31, doi: 10.9790/0853-1509022831.

6. Han CC, Liu R, Liu RR. Prevalence of Asthenopia and its Risk Factors in Chinese College Students. Int J Ophthalmol. 2013; 6(5): 718-722, doi: 10.3980/j.issn.2222-3959.2013.05.31, indexed in Pubmed: 24195055.

7. Hashemi H, Fotouhi A, Yekta A, et al. Global and Regional Estimates of Prevalence of Refractive Errors : Systematic Review and Meta-Analysis. J Curr Ophthalmol. 2018; 30(1): 3-22, doi: 10.1016/j. joc0.2017.08.009, indexed in Pubmed: 29564404.

8. Mowatt L, Gordon C, Santosh AB, et al. Computer vision syndrome and ergonomic practices among undergraduate university students. Int J Clin Pract. 2018; 72(1), doi: 10.1111/ijcp.13035, indexed in Pubmed: 28980750.

9. Khalaj M, Ebrahimi M, Shojai $P$, et al. Computer Vision Syndrome in Eleven to Eighteen-Year-Old Students in Oazvin. Biotechnol Health Sci. 2015; 2(3), doi: 10.17795/bhs-28234.

10. Sen A, Richardson SA. A Study of Computer-Related Upper Limb Discomfort and Computer Vision Syndrome. J Human Ergol. 2007; 36(2): 45-50, indexed in Pubmed: 18572794.

11. Charpe NA, Kaushik V. Computer Vision Syndrome (CVS): Recognition and Control In Software Professionals. J Human Ecol. 2009; 28: 67-69.

12. Shantakumari N, Eldeeb R, Sreedharan J, et al. Computer use and vision-related problems among university students in ajman, United arab emirate. Ann Med Health Sci Res. 2014; 4(2): 258-263, doi: 10.4103/2141-9248.129058, indexed in Pubmed: 24761249.

13. Shrivastava $S$, Bobhate P. Computer related health problems among software professionals in Mumbai: A cross-sectional study. Int $\mathrm{J}$ Health Allied Sci. 2012; 1(2): 74, doi: 10.4103/2278-344x.101684. 
14. Amirul FZ, Aquilah R, Lee ML, et al. Knowledge, Attitude and Practice of Computer Vision Syndrome among Staffs that use Video Display Terminal in a Faculty of a Malaysian Public University. Intl J Public Health Clin Sci. 2015; 2(1): 2289-7577.

15. Dios JRMd, Arrue BC, Ollero A, et al. Computer vision techniques for forest fire perception. Image Vis Comp. 2008; 26(4): 550-562, doi: 10.1016/j.imavis.2007.07.002.

16. Singh $\mathrm{H}$, Tigga M, Laad S, et al. Prevention of Ocular Morbidity among Medical Students by Prevalence Assessment of Asthenopia and its Risk Factors. J Evid Based Med Health. 2016; 3(15): 532-536, doi: 10.18410/jebmh/2016/122.

17. Zucker S. Computer Vision and Human Perception. J Chem Inf Model. 2013; 53: 1689-1699.

18. Ko P, Mohapatra A, Bailey IL. Effect of Font Size and Glare on Computer Tasks in Young and Older Adults. Optom Vis Sci. 2014; 91(6): 682-689, doi: 10.1097/0PX.0000000000000274, indexed in Pubmed: 24830373.

19. Rosenfield M. Computer vision syndrome: a review of ocular causes and potential treatments. Ophthalmic Physiol Opt. 2011; 31(5):
502-515, doi: 10.1111/j.1475-1313.2011.00834.x, indexed in Pubmed: 21480937.

20. Reddy SC, Low CK, Lim YP, et al. Computer vision syndrome: a study of knowledge and practices in university students. Nepal J Ophthalmol. 2013; 5(2): 161-168, doi: 10.3126/nepjoph.v5i2.8707, indexed in Pubmed: 24172549.

21. Nursyifa G, Santoso P. Computer Vision Syndrome among Call Center Employees at Telecommunication Company in Bandung. Althea Med J. 2016; 3(2): 181-185, doi: 10.15850/amj.v3n2.789.

22. Noreen K, Batool Z, Fatima T, et al. Prevalence of Computer Vision Syndrome andilts Associated Risk Factors among Under Graduate Medical Students. Pak J Ophthalmol. 2016; 140.

23. Chendilnathan C, Ramalingam P, Raja A, et al. Cross-sectional questionnaire study of ocular effects among IT professionals who use computers. Int J Med Publ Health. 2015; 5(1): 63, doi: 10.4103/2230-8598.151264.

24. Bali J, Navin N, Thakur BR. Computer vision syndrome: a study of the knowledge, attitudes and practices in Indian ophthalmologists. Indian J Ophthalmol. 2007; 55(4): 289-294, doi: 10.4103/0301-4738.33042, indexed in Pubmed: 17595478. 
